\title{
Increase in the Expression of an Alpha-Amylase Gene and Sugar Accumulation Induced during Cold Period Reflects Shoot Elongation in Hyacinth Bulbs
}

\author{
Azusa Sato ${ }^{1}$ and Hiroshi Okubo ${ }^{2}$ \\ Laboratory of Horticultural Science, Faculty of Agriculture, Kyushu University, Fukuoka 812-8581, \\ Japan \\ Kazuyuki Saitou
Laboratory of Plant Production Physiology, Faculty of Agriculture, Kyushu University, Fukuoka 812-
8581, Japan
}

AdDitIONAL INDEX wORDs. Hyacinthus orientalis, bulbous plants, dormancy, low temperature, carbohydrate metabolism

\begin{abstract}
Aвstract. The aim of this study was to investigate physiological and biochemical mechanisms of shoot elongation after cold period in hyacinth (Hyacinthus orientalis L. cv. Delft Blue). Hyacinth shoot rapidly elongated during hydro-culture period in cooled bulbs, but not in non-cooled bulbs. Alpha-amylase (EC 3.2.1.1.) is a key enzyme involved in starch hydrolysis. Alpha-amylase activity increased during the cold storage period and was low during rapid shoot elongation in hyacinth. In the non-cooled bulbs, its activity remained at the similar level. Sucrose content increased during the cold storage period in the shoot, but not in the scales. We, for the first time, isolated cDNA for cold-responsive alphaamylase gene (HoAmy1A, accession No. AB198975) from hyacinth, and presented that HoAmy1A expression increased in the scale during the cold storage period, but the level was very low during shoot elongation. We also found that promoter region of $\mathrm{HoAmy1A}$ contained CArG element, which is related to the response to low temperature. In tulip (Tulipa genesriana L.), the most studied bulbous plant, dramatic increase in alpha-amylase activity and translocation of sugars from the scales to shoot occurred during the growth stage, following cold treatment (Komiyama et al., 1997; Lambrechts et al., 1994). Our results suggest that there are two types (tulip and hyacinth types) of sprouting mechanisms in bulbous plants.
\end{abstract}

Many bulbous plants require a cold period to stimulate rapid shoot elongation under suitable growth conditions. When bulbs are planted outdoors in a temperate climate, their shoots grow quite slowly during the winter, then elongate rapidly in the spring. Since the manipulation of bulb temperature to control flowering is very important for the horticultural industry, cold treatment conditions have been studied extensively. Hyacinth is one of these flower bulbs, requires a cold period $\left(-0.5\right.$ to $10{ }^{\circ} \mathrm{C}$ for 10 to 18 weeks) for optimal shoot elongation in spring (De Hertogh and Le Nard, 1993). It has not been demonstrated, however, how the metabolism would proceed during the cold period for subsequent shoot elongation nor what connects the length of the cold period with shoot length after planting.

Many studies on the mechanisms of germination have been reported in cereal plants. During seed germination, alpha-amylase in the aleurone layer plays an important role in hydrolyzing the endosperm starch into metabolizable sugars, which provide the energy for the growth of shoots (Akazawa and Hara-Nishimura, 1985; Beck and Ziegler, 1989). There are also a few reports on alpha-amylase in bulbous plants. Tulip, one of the most studied bulbous plants, requires cold period as in hyacinth, alpha-amylase activity in the storage organ increases slightly during the

Received for publication 27 July 2005. Accepted for publication 6 Oct. 2005. We would like to acknowledge Dr. Takahiro Kusakabe, Dr. Jae Man Lee and the staff members of Laboratory of Silkworm Science (Kyushu University) for technical advice. Funding was received from the Kyushu University Foundation and Grant-in-Aid for Scientific Research (No.15380027) from the Ministry of Education, Science, Sports and Culture, Japan.

'Corresponding author. E-mail address: unos@agr.kyushu-u.ac.jp ${ }^{2}$ Professor.

${ }^{3}$ Associate Professor. cold period and increases dramatically during shoot elongation (Komiyama et al., 1997; Lambrechts et al., 1994). Lily (Lilium L. cultivars Casablanca and Mona) bulblets regenerated in vitro showed increase in alpha-amylase activity in response to low temperature (Shin et al., 2002). However, studies on alpha-amylase at the mRNA transcription level in bulbous plants have not been reported, in spite of some reports available on the enzyme activity.

Low temperature causes conversion of starch to sugars in many higher plants. For example, lily and tulip bulbs and potato (Solanum tuberosum L.) tubers cause increase in reducing sugars during the cold period involved with starch breakdown (Isherwood, 1973; Komiyama et al., 1997; Lambrechts et al., 1994; Matsuura-Endo et al., 2004; Miller and Langhans, 1990; Shin et al., 2002).

Gene transcription is commonly controlled by the interplay of promoter DNA of general and gene-specific components of the mRNA synthetic machinery (Orphanides etal., 1996). Cis-regulatory DNA elements involved in GA induction of alpha-amylase genes have been studied extensively in barley (Hordeum vulgare L.) and rice (Oryza sativa L.) (Gubler et al., 1995, 1997, 1999, 2002; Gómez-Cadenas et al., 2001; Skriver et al., 1991; Sutliff et al., 1993), GARE was reported as the GA response element. But there have been no reports on the promoter region of coldinduced alpha-amylase.

To demonstrate the cold-required sprouting mechanism in hyacinth bulbs, we investigated the effect of low temperature on the activity and gene expression of alpha-amylase, and the contents of starch and sugars in hyacinth bulbs. And we analyzed the promoter regions of HoAmylA, whose transcription was induced by low temperature. 


\section{Materials and Methods}

Plant materials and growth conditions. Hyacinth bulbs, the products of The Netherlands, were stored at $5{ }^{\circ} \mathrm{C}$ (cooled) or $25^{\circ} \mathrm{C}$ (non-cooled) for 12 weeks from 1 Oct. and then grown on aluminum trays with distilled water (hydro-culture) at $25^{\circ} \mathrm{C}$ with $70 \%$ relative humidity under a natural light-dark photoperiod for 5 weeks in the phytotron of Kyushu Univ., Fukuoka, Japan. Six bulbs were harvested each time $(0,7,12,13,15$, and 17 weeks) and separated into scales, leaves and basal plate. They were frozen in liquid nitrogen and stored at $-80^{\circ} \mathrm{C}$ until analysis.

ALPHA-AMYLASE ACTIVITY ASSAYS. Scales of fourbulbs per assay were used and extraction was conducted per bulb. Frozen powder tissue $(500$ to $600 \mathrm{mg}$ ) taken from the scales was homogenized at 0 to $4{ }^{\circ} \mathrm{C}$ in $2 \mathrm{~mL}$ buffer containing $50 \mathrm{~mm}$ Hepes- $\mathrm{NaOH}$ (pH7.5), $10 \mathrm{~mm} \beta$-mercaptoethanol. The enzyme extract $(5 \mu \mathrm{L})$ was mixed with $25 \mu \mathrm{L}$ of $200 \mathrm{~mm}$ citrate-phosphate buffer (pH 4.5) containing $4 \mathrm{~mm} \mathrm{CaCl}_{2}$, and the reaction was started by adding $30 \mu \mathrm{L}$ of BPNPG7 (Megazyme, Bray, Ireland) as a substrate. Then $30 \mu$ Lof $\alpha$-glucosidase, Amylase HR Reagent (Megazyme), was added and conducted according to manufacturer's instructions. The activity was determined as liberated $\rho$-nitrophenolate detected spectrophotometrically at $405 \mathrm{~nm}$ (Sirou et al., 1990) with a spectrophotometer (model V-530; JASCO, Tokyo). One unit of alpha-amylase activity was taken to be as the amount of enzyme required to provide $1 \mu \mathrm{mol}$ of paranitrophenol per minute. Protein concentrations were determined using a Bio-Rad Protein assay kit (Bio-Rad, Richmond, Calif.) with bovine serum albumin as a standard.

CARBohydrate ANALYSIs. Scales and shoots of four hyacinth bulbs per analysis were used and the analysis was conducted per bulb. Frozen powder tissue (500 to $600 \mathrm{mg}$ ) was extracted at $60{ }^{\circ} \mathrm{C}$ in $2 \mathrm{~mL}$ of $80 \%(\mathrm{v} / \mathrm{v})$ ethanol following the procedure described by Lambrechts et al. (1994). After each extraction the suspension was centrifuged at $2000 g_{\mathrm{n}}$ for $5 \mathrm{~min}$. The supernatants were pipetted off and combined. The ethanol was evaporated at 50 ${ }^{\circ} \mathrm{C}$. The residue was twice submitted to a 5 chloroform : 8 water extraction $(\mathrm{v} / \mathrm{v})$. The water phases were combined for analysis of sucrose, glucose, and fructose. The ethanol-insoluble pellet was used for analysis of starch. Sugars and starch were analyzed using F-kit (Roche Diagnostics, Mannheim, Germany). Statistical analysis was performed using the Tukey's honestly significantly different test.

ISOLATION OF CDNACLONES FOR ALPHA-AMYLASE GENES. FrOZEn scales from hyacinth bulbs cooled for 7 weeks were ground into fine powder in liquid nitrogen, and total RNA was extracted by phenol/SDS method (Ausubel et al., 1997), and then treated with DNaseI (RNase free, Roche Diagnostics) to remove the contamination of genomic DNA. First-strand cDNA synthesis using as template $900 \mathrm{ng}$ total RNA from hyacinth scales was performed in a $20-\mu \mathrm{L}$ volume with RNA PCR kit (AMV version 2.1; Takara, Otsu,Japan). Each cDNA was used as a template for a PCR reaction with degenerated primers, designed from consensus sequences of corn (Zea mays L.) (L25805), barley (K02638), rice (M24286), arabidopsis [Arabidopsis thaliana (L.) Heynh.] (AY117294), and potato (M79328). The forward primer consisted of a 23-mer of the sequence 5'-CAG (A, G)G (G, T)TT CAA (C, T)TG GGA GTC (A, G)TG-3'. The reverse primer was a 24-mer of the sequence 5'-(C, G)AC (C, G)CC CTT GGT (C, G)GT GAA ATC AAA-3'. The conditions of PCR were as follows: $30 \mathrm{~s} 94^{\circ} \mathrm{C}, 30 \mathrm{~s} 57^{\circ} \mathrm{C}$, $1 \mathrm{~min} 30 \mathrm{~s} 72{ }^{\circ} \mathrm{C}$ for 30 cycles, and $10 \mathrm{~min} 72^{\circ} \mathrm{C}$ by using Ex Taq (Takara). The PCR products were electrophoresed on $1.5 \%$ agarose gel, and $\approx 720$-bp DNA fragments were extracted using QIA Quick Gel extraction kit (Qiagen, Hilden, Germany). The purified DNA was cloned into pGEM-T Easy-vector (Promega, Madison, Wis.) and the nucleotide sequences were determined using a genetic analyzer (ABI PRISM 310; Applied Biosystem, Foster City, Calif.). 5' - and 3'-RACEs were carried out with BD SMART RACE cDNA amplification kit (Clontech, Palo Alto, Calif.) according to manufacturer's instructions. 5'-RACE involved PCR using 5'-ACT TGT CAG GTC ACT CCA GAT CTC TGC AAC-3' as a reverse primer. $3^{\prime}-\mathrm{RACE}$ involved PCR using 5'TCA AAT GTG TCG CGG ACA TAG TCA TAA ACC-3' as a forward primer. In order to obtain further sequences of $3^{\prime}$ region, primer-walking was conducted using 5'-TGT TGC AGA GAT CTG GAG TGA CCT GAC AAG-3'.

SEMi-Quantitative RT-PCR. Frozen scales of three bulbs per experiment were used. Total RNA extraction and cDNA synthesis were conducted per bulb. First-strand cDNA synthesis using as template $900 \mathrm{ng}$ total RNA from hyacinth scales was performed in a 20- $\mu \mathrm{L}$ volume with RNA PCR kit (AMV version 2.1; Takara). Reverse transcription was performed using mixed primer \{oligo dT/random primer [24:1 (v/v)]\}. Each cDNA diluted to $1 / 50$ concentration and used as a template for a PCR reaction with degenerated primers. The sequence of HoAmylA forward primer was a $5^{\prime}$-TCA AAT GTG TCG CGG ACA TAG TCA TAA ACC-3' and that of the reverse primer was a $5^{\prime}$-ACT TGT CAG GTC ACT CCA GAT CTC TGC AAC-3', and these were designed for 387-bp fragment. HoAmy $1 B$ forward primer was a 5'-TTA AGG GTG AAT GAT ATT GCT AG-3', and its reverse primer was a 5'-TTA AGC CAG TTC AGC CAC T-3', and these were designed for 437-bp fragment. 18S rRNA was used as an internal control (Sato et al., 2005). Number of cycles was set at 20, 25, 30, 31, and 32. Those PCR products were quantified using an imager (Molecular Imager FX; Bio-Rad). Experiments were repeated three times.

INVERSE PCR FOR CLONING OF GENOMIC FRAGMENTS OF HoAmy1A AND HoAmy1B. Genomic promoter regions of $H o A m y l A$ and $H o A m y l B$ genes were obtained by inverse PCR as described by Triglia et al. (1988). Genomic DNA was extracted as described by Kobayashi et al. (1998) from hyacinth leaves of shoot and digested with restriction enzyme, EcoRI or TaqI. The DNA digests were used as templates for inverse PCR using the primers HoAmyP-In5' (5'-TAG GGC CTA TAA TTA TGG TAT CCT GTT AAG-3'), HoAmyP-InRT (5'-CAA TTT CCG GCC TAT AAA ATC TGA TGC ATC-3') and KOD-Plus- (Toyobo, Osaka, Japan). The PCR products were inserted into pZErO-2 vector (Invitrogen, Carlsbad, Calif.) and their nucleotide sequences were determined.

\section{Results}

SHOOT GROWTH OF HYACINTH BULBS DURING TEMPERATURE TREATMENT AND HYDRO-CULTURE PERIOD. Shootelongation in non-cooled bulbs was low during temperature treatment and hydro-culture periods (Fig. 1). Cooled bulbs showed a similar growth pattern to non-cooled bulbs during temperature treatment period, but they grew rapidly and the shoots reached about twice the length of those of the non-cooled bulbs at 5 weeks of hydro-culturing. Neither cooled nor non-cooled bulbs flowered until 5 weeks of hydro-culturing.

Alpha-amylase activity in the SCALES OF hyacinth bulbs. Alpha-amylase activity remained at the similar level throughout temperature treatment and hydro-culture period in the non-cooled 


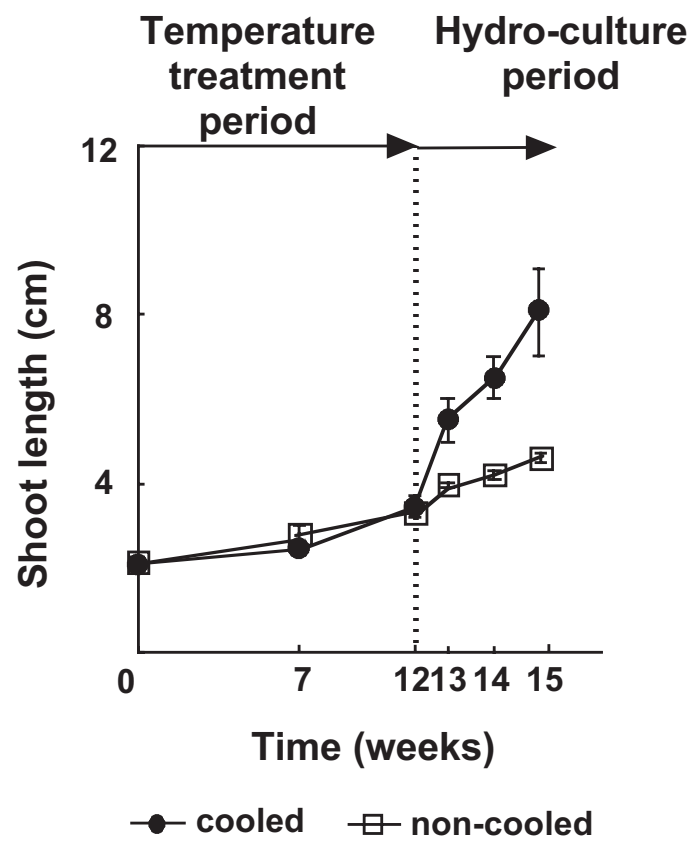

Fig. 1. Shoot length of hyacinth bulbs during temperature treatment and hydroculture periods. Bulbs were dry-stored at $5{ }^{\circ} \mathrm{C}$ (cooled treatment) or $25^{\circ} \mathrm{C}$ (non-cooled treatment) for 12 weeks, and grown at $25^{\circ} \mathrm{C}$ for 5 weeks by hydro-culture. Values are means \pm SD of four bulbs.

bulbs, whereas it increased during cold treatment period in the cooled bulbs (Fig. 2). The activity considerably decreased after the onset of hydro-culture at $25^{\circ} \mathrm{C}$ and reached levels similar to those observed in the non-cooled bulbs within 1 week.

SuCrose, GLuCOSE, FRUCTOSE, AND STARCH CONTENTS IN THE SCALES AND SHOOT LEAVES. Starch was the major carbohydrate in the scales (Table 1). Starch contents were lower in the cooled bulbs than in the non-cooled bulbs at 12 weeks of temperature treatment. Sucrose contents in cooled and non-cooled bulbs showed similar values at 12 weeks of temperature treatment, and decreased after temperature treatment (Table 1). The amounts of glucose and fructose were comparatively low. Glucose showed the largest content at 12 weeks in the cooled treatment bulbs. There was no difference in the fructose content (Table 1). Sucrose was the major carbohydrate in the leaves of shoots throughout temperature treatment and hydro-culture periods (Fig. 3A, 3B, $3 \mathrm{C}, 3 \mathrm{E})$. Sucrose content increased during temperature treatment and decreased during hydro-culture in cooled plants, whereas it increased gradually in non-cooled plants (Fig. 3A). Glucose content increased during temperature treatment in cooled plants, but not in non-cooled plants (Fig. 3B). Little fructose was detected during temperature treatment (Fig. 3C). After the onset of hydroculture, glucose and fructose contents gradually increased in accordance with the decrease in sucrose content in cooled plants, but they remained at low levels in non-cooled plants (Fig. 3A, 3B, 3C). There was no difference in the total amount of soluble sugars (sucrose, glucose, and fructose) in cooled and non-cooled plants at 7 weeks of temperature treatment period, but the content in the cooled plants was approximately twice that of the noncooled plants at 12 weeks of treatment period (Fig. 3D). The total amount of soluble sugars remained constant in the cooled and non-cooled plants during hydro-culture (Fig. 3D). Starch content was relatively low in the shoot leaves (Fig. 3E).

ISOLATION OF A CDNA FOR ALPHA-AMYLASE GENES IN THE SCALES. We cloned a 714-bp fragment of from the scales of cooled hyacinth bulbs and its full-length cDNA was obtained using a

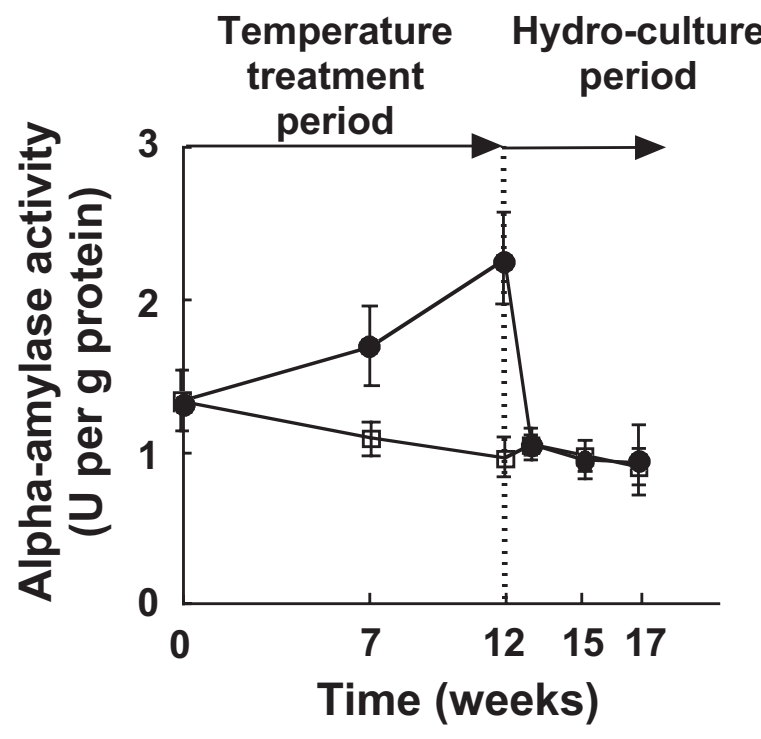

- cooled $\square$ non-cooled

Fig. 2. Alpha-amylase activity in the scales of hyacinth bulbs during temperature treatment and hydro-culture periods. Bulbs were stored at $5{ }^{\circ} \mathrm{C}$ (cooled treatment) or $25^{\circ} \mathrm{C}$ (non-cooled treatment) for 12 weeks, and grown at $25^{\circ} \mathrm{C}$ for 5 weeks by hydro-culture. Values are means \pm SD of independent extracts from four bulbs.

Table 1. Starch, sucrose, glucose, and fructose contents in the scales of hyacinth bulbs at 12 weeks of temperature treatment at $5{ }^{\circ} \mathrm{C}$ (cooled) and $25^{\circ} \mathrm{C}$ (non-cooled), and at 3 weeks of hydro-culturing after temperature treatment.

\begin{tabular}{lcccc}
\hline & Starch & Sucrose & Glucose & Fructose \\
\cline { 2 - 5 } & \multicolumn{3}{c}{$(\mathrm{g} / 100 \mathrm{~g}$ fresh $\mathrm{wt})$} & \\
\hline $\begin{array}{c}12 \text { weeks of cooled } \\
\text { treatment }\end{array}$ & $11.1 \mathrm{~b}^{\mathrm{z}}$ & $1.04 \mathrm{~b}$ & $0.0300 \mathrm{~b}$ & $0.048^{\mathrm{Ns}}$ \\
$\begin{array}{c}12 \text { weeks of non-cooled } \\
\text { treatment }\end{array}$ & $13.3 \mathrm{c}$ & $1.02 \mathrm{~b}$ & $0.0078 \mathrm{a}$ & $0.051^{\mathrm{Ns}}$ \\
$\begin{array}{c}\text { 3eeks of culturing after } \\
\text { cooled treatment }\end{array}$ & $9.4 \mathrm{a}$ & $0.68 \mathrm{a}$ & $0.0068 \mathrm{a}$ & $0.054^{\mathrm{Ns}}$ \\
$\begin{array}{c}3 \text { weeks of culturing after } \\
\text { non-cooled treatment }\end{array}$ & $11.2 \mathrm{~b}$ & $0.61 \mathrm{a}$ & $0.0188 \mathrm{a}$ & $0.037^{\mathrm{ss}}$
\end{tabular}

${ }_{\text {zStatistical analysis was performed using the Tukey's HSD test. Means }}$ followed by the same letter are not significantly different at $P<0.05$. ss Nonsignificant.

5'- and 3'-RACEs protocol. The gene corresponding its cDNA was designated HoAmylA (DDBJ accession No. AB198975). The HoAmyl A cDNA sequence contained an open reading frame coding for a putative protein of 419 amino acids. An amino acid alignment was performed with DNASIS software using HoAmy $1 \mathrm{~A}$ and other amino acid sequences identified as alpha-amylases (data not shown). HoAmylA showed identity to barley2 (Swiss-Prot/PIR P04063) (66\%), a mung bean (Vigna radiata L.) (Swiss-Prot/PIR 1803517A) (64\%), potato Amy23 (GenBank/EMBL/DDBJ M79328) (47\%), and apple (Malus $\times$ domestica Borkh.) Amy8 (GenBank/EMBL/DDBJ AF153828) (46\%).

EXPRESSION OF HoAmy1A IN THE SCALES. The expression of HoAmylA estimated by a semi-quantitative RT-PCR method in the scales in cooled bulbs increased markedly during temperature treatment at $5{ }^{\circ} \mathrm{C}$, but decreased rapidly and remained low after the onset of hydro-culturing at $25^{\circ} \mathrm{C}$ (Fig. 4A). Expression of HoAmylA in non-cooled scales was always low (Fig. 4B). 18S rRNA was used as an internal control. 
A

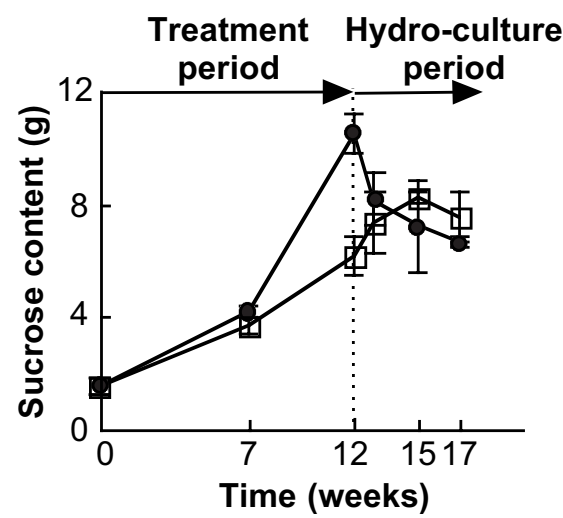

B

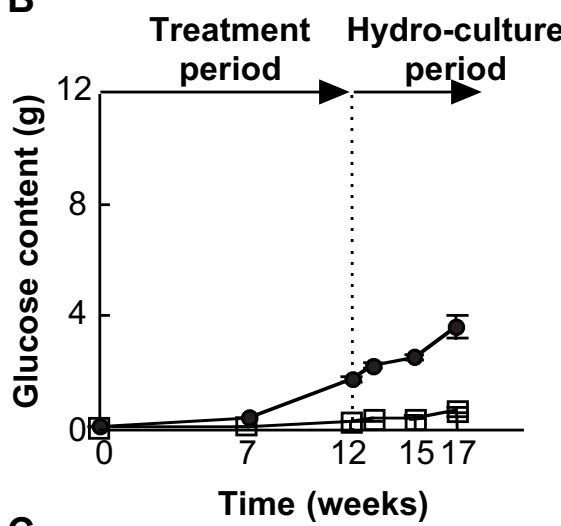

C

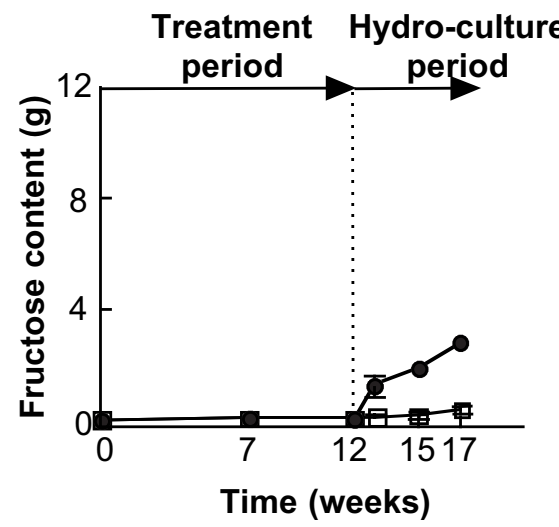

D

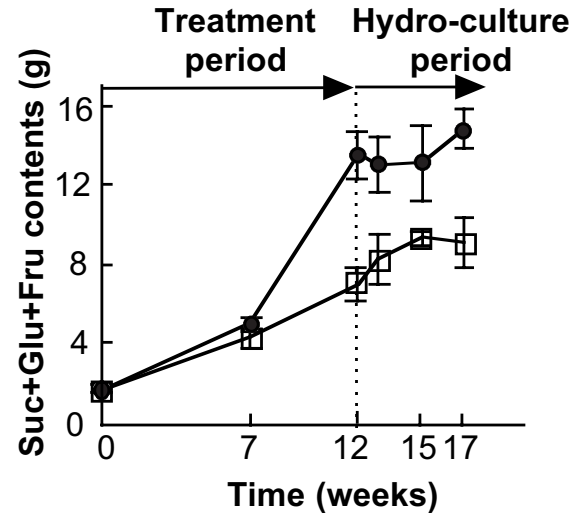

E

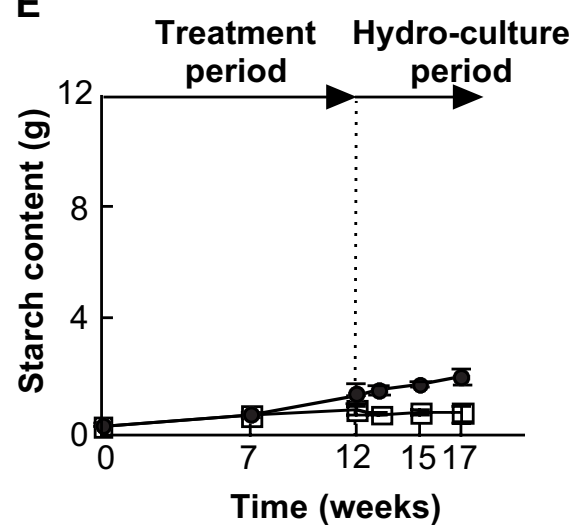

○- cooled ஐ non-cooled

of HoAmylA from -300 through to -623 , or from -653 through -669 .

Computational analysis of the $5^{\prime}$-upstream regions of HoAmylA and HoAmylB, using PLACE Web Signal Scan program, could not identify classical TATA boxes, common core promoter elements. GARE (TAACAG/AA), a GA response element, was located between -103 and -97 of HoAmyl B (TAACAGA), but not HoAmyl A (CAGCAGA) (Fig. 5). CArG (CCWWWWWWGG; W=A or T) is cold-responsive element; this box motif was located between -527 and -536 in the upstream region of the HoAmylA. HoAmylB did not contain CArG in the upstream region (Fig. 5) and its expression was not detected during the cold period at all (data not shown).

\section{Discussion}

Alpha-amylase is a key enzyme involved in the hydrolysis of starch into sugars that can be metabolized. It plays an important role in germination and sprouting in many higher plants (Akazawa and Hara-Nishimura, 1985; Beck and Ziegler, 1989; Hagenimana and Simard, 1994; Karrer et al., 1991). Sucrose is utilized as an energy source and is essential for sprouting and shoot elongation. Our findings that alpha-amylase activity and gene expression increased during a cold treatment period and low during rapid shoot elongation (Fig. 1, Fig. 2, Fig. 4) were unexpected from previous reports that alpha-amylase activity increases at the time of germination or sprouting and during subsequent growth in many plants (Akazawa and Hara-Nishimura, 1985; Beck and Ziegler, 1989; Hagenimana and Simard, 1994; Komiyama et al., 1997). The changes in transcription level of HoAmy $1 \mathrm{~A}$ corresponded with that in alpha-amylase activity (Fig. 2, Fig. 4) suggesting that the enzymatic activity is mainly regulated by mRNA level.

No sucrose accumulation in the scales was caused by low temperature, whereas starch content decreased during cooling period (Table1), suggesting that most sucrose is transported from the scales to the shoot during cold period in hyacinth. Starch breakdown and

Fig. 3. (A) Sucrose; (B) glucose; (C) fructose; (D) total of sucrose, glucose, and fructose; and (E) starch contents in the shoot leaves of a hyacinth bulb during temperature treatment and hydro-culture periods. Bulbs were dry-stored at $5{ }^{\circ} \mathrm{C}$ (cooled treatment) or $25^{\circ} \mathrm{C}$ (non-cooled treatment) for 12 weeks, and grown at $25^{\circ} \mathrm{C}$ for 5 weeks by hydro-culture. Values are means \pm SD of independent extracts from four bulbs.

ISOLATION AND CHARACTERIZATION OF THE PROMOTER REGIONS OF TWO ALPHA-AMYLASE GENES. A genomic DNA fragment around the 5'-flanking sequence was amplified by inverse PCR to obtain the 5'-upstream region of the HoAmylA cDNA. Two fragments were obtained; one was the 5'-upstream region of the HoAmylA (DDBJ accession No. AB222269, 1042-bp), the other (DDBJ accession no. AB222270, 697-bp) was that of another putative gene for alpha-amylase (designated as $H o A m y l B$ ) based on comparing each exon sequence with the HoAmylA cDNA. Partial sequences of the $5^{\prime}$-upstream regions of HoAmylA and $H o A m y l B$ are shown in Fig. 5. The region of HoAmylA from -1 through -299 showed $89.2 \%$ similarity to that of HoAmy $1 B$ from -1 through -297, while HoAmylB had no region similar to that sucrose accumulation in the scales of tulip occurred during cold period, and total amount of sugars (sucrose, glucose and fructose) dramatically increased after planting (Lambrechts et al., 1994). It is therefore indicated that carbohydrate metabolism in hyacinth is different from that in tulip. The more the sucrose accumulation in shoot leaves was, the more the shoot leaves elongated in hyacinth (Fig. 1, Fig. 3A). And the longer the cold treatment period was, the more sucrose accumulation in shoot leaves was (Fig. 3A). From these results, we suppose that sucrose accumulation might recognize cold requirement, and thus the shoot length might reflect the length of cold period in hyacinth.

Carbohydrates in the endosperm of seeds are completely consumed for germination. Mother-bulbs of tulips are replaced 
A
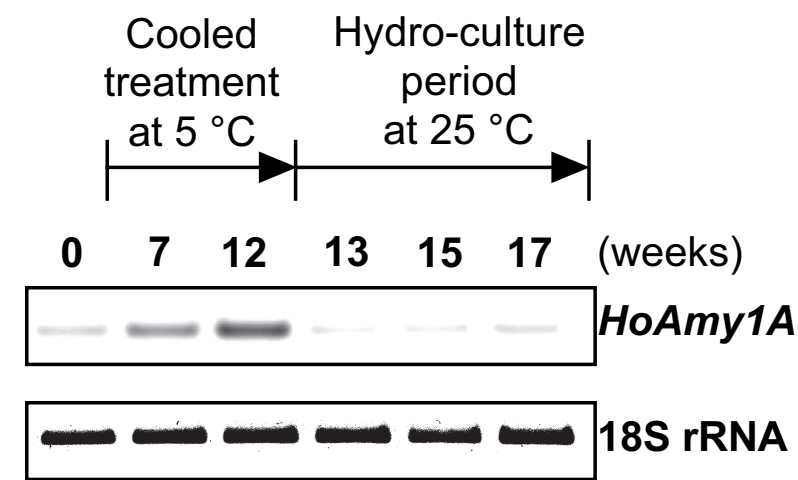

B

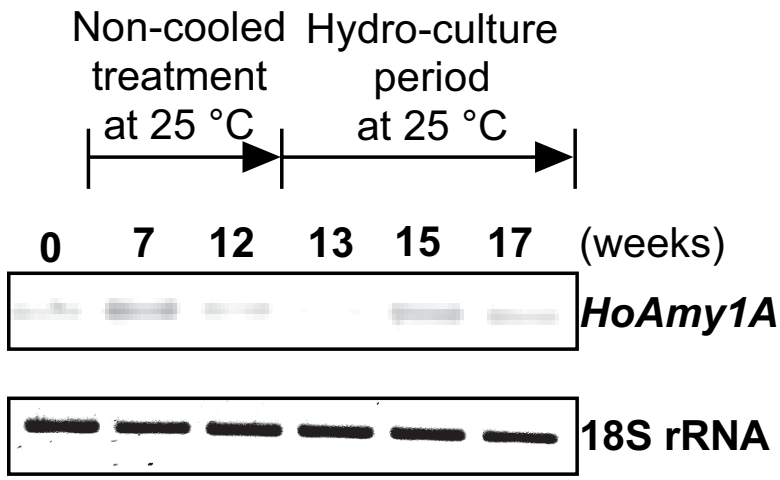

Fig. 4. The expression of HoAmylA in the scales of hyacinth bulbs during temperature treatment and hydro-culture periods. Bulbs were dry-stored for (A) $5{ }^{\circ} \mathrm{C}$ or (B) $25^{\circ} \mathrm{C}$ for 12 weeks, and grown at $25^{\circ} \mathrm{C}$ for 5 weeks by hydroculture. $18 \mathrm{~S}$ rRNA was amplified as controls for equal amount of cDNAtemplate. Numbers of PCR cycles for HoAmy1A and 18S rRNA were set at 31 and 25, respectively. Experiments were repeated three times with similar results; one representative data set is shown.

by new daughter-bulbs every year, indicating that the carbohydrates in the mother-bulbs are completely consumed on an annual basis. In these seeds and bulbs, the amount of carbohydrates in the shoot gradually increases during shoot elongation (Lambrechts et al., 1994; Morris and Arthur, 1984). Hyacinth bulbs have perennial scales, and a part of the carbohydrate in the scales is preserved for years. The difference in whether the increase in alpha-amylase leading degradation of sugars via starch hydrolysis and transportation to the shoot occurs during or after the cold period may reflect the difference in the bulb replacement system. Its relationship to hyacinth being a more rapidly flowering species than tulip after completion of the cold requirement may be considerable (De Hertogh, 1996). The earlier flowering in hyacinth might be due to early alpha-amylase induction and sugar transportation to the shoots during cold storage period. We suggest that there are thus two types of sprouting mechanisms. In one, alpha-amylase activity in the storage organ and sugars in the shoot increase after planting (representative of the majority of plant species). In the other, alpha-amylase activity in the storage organ and sugars in the shoot increase during cold period. This is the first report to clearly illustrate the occurrence of the latter sprouting mechanism.

We showed that HoAmylA was expressed in response to low temperature. To explore the mechanism of cold-responsive HoAmylA expression, we investigated the 5'-upstream regions of HoAmylA. In eukaryotic protein-coding genes, promoter ele-

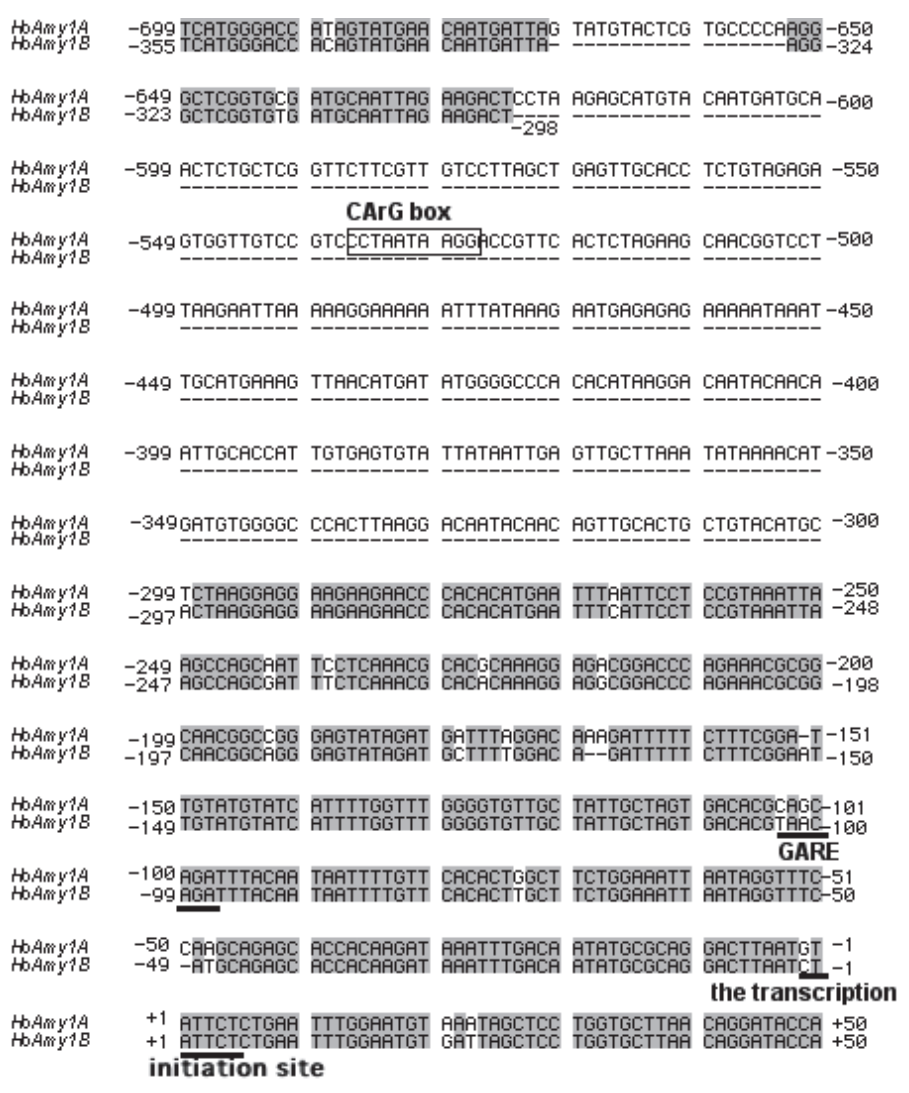

Fig. 5. Nucleotide sequences of the promoter region of hyacinth alpha-amylase genes (HoAmylA, AB222269; HoAmy1B, AB222270) with parts of their 5'untranslated regions. Putative transcription factor binding sites and transcription initiation sites are labeled. The DNASIS software was used to make the alignment. Identical nucleotides are shaded in gray. Dashed lines indicate gaps introduced to achieve maximum alignment.

ments are classified into two categories: common core promoter elements that are needed for basal transcription initiation; and gene-specific regulatory elements located upstream (Roeder, 1996). The core promoter is located near or at the transcription initiation site. A TATA box is essential in most cases. However, many genes lack a TATA box at the expected positions (Azizkhan et al., 1993). In some TATA-less promoters, an initiator element that overlaps the transcription start site compensates for the lack of a TATA box, and directs basal transcription initiation (Smale, 1997; Smale and Baltimore, 1989; Smale et al., 1998). Our results showed that the $5^{\prime}$-upstream regions of neither HoAmylA nor HoAmy $1 B$ had classical TATA boxes. However, putative initiator motifs were located overlapping the transcription initiation sites between -2 and +5 in both HoAmylA and HoAmylB .

The expression of $H o A m y l B$ was much less than that of HoAmyl A during cold period, suggesting that some sequences of promoter regions of HoAmylA different from HoAmylB should contain gene-specific regulatory elements for cold-induced gene expression. There have been no reports on the promoter region of cold-induced alpha-amylase, neither in bulbous or other plants. We here report on two promoter regions of alpha-amylase genes, HoAmylA is cold-responsiveness, and HoAmylB is not. Some studies have suggested that many cold-responsive genes have in their promoter regions one or several copies of the CRT/DRE cis-element, which has the core sequence CCGAC (Stockinger et al., 1997; Yamaguchi-Shinozaki and Shinozaki, 1994). A family of transcription factors, CBFs or DREB1s, binds to this element and activates transcription of the downstream cold and dehydra- 
tion-responsive genes (Liu et al., 1998; Stockinger et al., 1997). HoAmylA had no CRT/DRE cis-element in the promoter region, suggesting that HoAmyl A expression is controlled independently in this pathway.

Another report about cold-induced genes is on the floweringtime gene SOC1 (Borner et al., 2000; Lee et al., 2000: Samach et al., 2000). Extended exposure to low temperature is required for flowering in arabidopsis Hepworth et al., 2002, as well as for shoot elongation in hyacinth or tulip. FLC is a transcription factor (Michaels and Amasino, 1999) and the mRNA level is reduced in response to low temperature ( 2 to $4{ }^{\circ} \mathrm{C}$ ) (Gendall et al., 2001; Michaels and Amasino, 1999). FLC binds to CArG (Hepworth et al., 2002) and acts as a negative regulator of SOC1 in arabidopsis (Hepworth et al., 2002, Lee et al., 2000; Samach et al., 2000). The expression of SOC1 increases under low temperature conditions due to the reduction of FLC. Our results showed that HoAmylA has a CArG motif in the promoter region, suggesting that the expression of HoAmylA might be regulated by a similar mechanism to that mentioned above.

We propose based on the results in this study that 1) starch in hyacinth scales is hydrolyzed by cold-induced alpha-amylase, and sugars are transported to the shoot during cold period, 2) sucrose accumulation might recognize cold requirement, and thus the shoot length might reflect the length of cold period in hyacinth, and 3) there are two types (tulip- and hyacinth-types) of sprouting mechanisms in bulbous plants.

\section{Literature Cited}

Akazawa, T. and I. Hara-Nishimura. 1985. Topographic aspect of biosynthesis, extracellular secretion and intracellular storage of protein in plant cells. Annu. Rev. Plant. Physiol. 36:441-472.

Ausubel, F.M., R. Brent, R.E. Kingston, D.D. Moore, J.G. Seigman, J.A. Simth, and K. Struhl. 1997. Current protocols in molecular biology. Wiley, New York

Azizkhan, J.C., D.E. Jensen, A.J. Peirce, and M. Wade. 1993. Transcription from TATA-less promoters: Dihydrofolate reductase as a model. Crit. Rev. Eukaryotic Gene Expression 3:229-254.

Beck, E. and P. Ziegler. 1989. Biosynthesis and degradation of starch in higher plants. Annu. Rev. Plant. Physiol. Plant. Mol. Biol. 40:95-117.

Borner, R., G. Kampmann, J. Chandler, R. Gleissner, E. Wisman, K. Apel, and S. Melzer. 2000. A MADS domain gene involved in the transition to flowering in Arabidopsis. Plant J. 24:591-599.

De Hertogh, A. 1996. Holland bulb forcer's guide, 5th ed. Intl. Flower Bulb Centre, Hillegom, The Netherlands.

De Hertogh, A. and M. Le Nard. 1993. The physiology of flower bulbs. Elsevier, Amsterdam, The Netherlands.

Gendall, A.R., Y.Y. Levy, A. Wilson, and C. Dean. 2001. The vernalization 2 gene mediates the epigenetic regulation of vernalization in Arabidopsis. Cell 107:525-535.

Gómez-Cadenas, A., R. Zentella, T.D. Sutliff, and T.H.D. Ho. 2001. Involvement of multiple cis-elements in the regulation of GA responsive promoters: Definition of a new cis-element in the Amy32b gene promoter of barley (Hordeum vulgare). Physiol. Plant. 112:211-216.

Gubler, F., P.M. Chandler, R.G. White, D.J. Llewellyn, and J.V. Jacobsen. 2002. Gibberellin signaling in barley aleurone cells: Control of SLN1 and GAMYB expression. Plant Physiol. 129:191-200.

Gubler, F., R. Kalla, J.K. Roberts, and J.V. Jacobsen. 1995. Gibberellinregulated expression of a $m y b$ gene in barley aleurone cells: Evidence for Myb transactivation of a high-pI $\alpha$-amylase gene promoter. Plant Cell 7:1879-1891.

Gubler, F., D. Raventos, M. Keys, R. Watts, J. Mundy, and J.V. Jacobsen. 1999. Target genes and regulatory domains of the GAMYB transcriptional activator in cereal aleurone. Plant J. 17:1-9.
Gubler, F., R.J. Watts, R. Kalla, P. Matthews, M. Keys, and J.V. Jacobsen. 1997. Cloning of a rice cDNA encoding a transcription factor homologous to barley GAMYB. Plant Cell Physiol. 38:362-365.

Hagenimana, V. and R.E. Simard. 1994. Amylolytic activity in germinating sweetpotato (Ipomoea batatas L.) roots. J. Amer. Soc. Hort. Sci. 119:313-321.

Hepworth, S.R., F. Valverde, D. Ravenscroft, A. Mouradov, and G. Coupland. 2002. Antagonistic regulation of flowering-time gene SOC1 by CONSTANS and FLC via separate promoter motifs. EMBO J. 21:4327-4337.

Isherwood, F.A. 1973. Starch-sugar interconversion in Solanum tuberosum. Phytochemistry 12:2579-2591.

Karrer, E.E., J.C. Litts, and R.L. Rodriguez. 1991. Differential expression of $\alpha$-amylase genes in germinating rice and barley seeds. Plant Mol. Biol. 16:797-805.

Kobayashi, N., T. Horikoshi, H. Katsuyama, T. Handa, and K. Takayanagi. 1998. A simple and efficient DNA extraction method from the plants, especially from woody plants. Plant Tissue Cult. Biotechnol. 4:76-80.

Komiyama, S., T. Yamazaki, E. Hori, Y. Shida, A. Murayama, T. Ikarashi, and T. Ohyama. 1997. Degradation of storage starch in tulip bulb scales induced by cold temperature. Jpn. J. Soil Sci. Plant Nutr. 68:23-29.

Lambrechts, H. and D. Kollöffel. 1993. Soluble and insoluble invertase activity in elongating Tulipa gesneriana flower stalks. Physiol. Plant. 89:830-834.

Lambrechts, H., F. Rook, and C. Kollöffel. 1994. Carbohydrate status of tulip bulbs during cold-induced flower stalk elongation and flowering. Plant Physiol. 104:515-520.

Lee, H., S. Suh, E. Park, E. Cho, J.H. Ahn, S. Kim, J.S. Lee, Y.M. Kwon, and I. Lee. 2000. The AGAMOUS-LIKE 20 MADS domain protein integrates floral inductive pathways in Arabidopsis. Genes Dev. 14:2366-2376.

Liu, Q., Y. Sakuma, H. Abe, M. Kasuga, S. Miura, K. Yamaguchi-Shinozaki, and K. Shinozaki. 1998. Two transcription factors, DREB1 and DREB2, with an EREBP/AP2 DNA binding domain, separate two cellular signal transduction pathways in drought- and low temperatureresponsive gene expression, respectively, in Arabidopsis. Plant Cell 10:1391-1406.

Matsuura-Endo, C., A. Kobayashi, T. Noda, S. Takigawa, H. Yamauchi, and M. Mori. 2004. Changes in sugar content and activity of vacuolar acid invertase during low-temperature storage of potato tubers from six Japanese cultivars. J. Plant Res. 117:131-137.

Michaels, S.D. and R.M. Amasino. 1999. FLOWERING LOCUS C encodes a novel MADS domain protein that acts as a repressor of flowering. Plant Cell 11:949-956.

Miller, W.B. and R.W. Langhans. 1990. Low temperature alters carbohydrate metabolism in easter lily bulbs. HortScience 25:463-465.

Morris, D.A. and E.D. Arthur. 1984. Invertase activity in sinks undergoing cell expansion. Plant Growth Regulat. 2:327-337.

Orphanides, G., T. Lagrange, and D. Reinberg. 1996. The general transcription factors of RNA polymerase II. Genes Dev. 10:2657-2683.

Roeder, R.G. 1996. The role of general initiation factors in transcription by RNA polymerase II. Trends Biochem. Sci. 21:327-335.

Samach, A., H. Onouchi, S.E. Gold, G.S. Ditta, Z. Schwarz-Sommer, M.F. Yonofsky, and G. Coupland. 2000. Distinct roles of CONSTANS target genes in reproductive development of Arabidopsis. Science 288:1613-1616.

Sato, A., K. Saitou, and H. Okubo. 2005. Estimation of actin and 18S rRNA as internal controls of RNA in Hyacinth (Hyacinthus orientalis L.). J. Fac. Agr. Kyushu Univ. 51:103-108.

Shin, K.S., S.D. Chakrabarty, and K.Y.Peak. 2002. Sprouting rate, change of carbohydrate contents and related enzymes during cold treatment of lily bulblets regenerated in vitro. Scientia Hort. 96:195-204.

Sirou, Y., D. Lecommandeur, and C. Laurière. 1990. Specific enzymatic microassays of $\alpha$-amylase and $\beta$-amylase in cereals. J. Agr. Food Chem. 38:171-174. 
Skriver, K., F.L. Olsen, J.C. Rogers, and J. Mundy. 1991. Cis-acting DNA elements responsive to gibberellin and its antagonist abscisic acid. Proc. Natl. Acad. Sci. USA 88:7266-7270.

Smale, S.T. 1997. Transcription initiation from TATA-less promoters within eukaryotic protein-coding genes. Biochim. Biophys. Acta 1351:73-88.

Smale, S.T. and D. Baltimore. 1989. The 'initiator' as a transcription control element. Cell 57:103-113.

Smale, S.T., A. Jain, J. Kaufmann, K.H. Emami, K. Lo, and I.P. Garraway. 1998. The initiator element: a paradigm for core promoter heterogeneity within metazoan protein-coding genes. Cold Spring Harb. Symp. Quant. Biol. 63:21-31.

Stockinger, E.J., S.J. Gilmour, and M.F. Thomashow. 1997. Arabidop- sis thaliana $\mathrm{CBF} 1$ encodes an AP2 domain-containing transcription activator that binds to the C-repeat/DRE, a cis-acting DNA regulatory element that stimulates transcription in response to low temperature and water deficit. Proc. Natl. Acad. Sci. USA 94:1035-1040.

Sutliff, T.D., M.B. Lanahan, and T.H.D. Ho. 1993. Gibberellin treatment stimulates nuclear factor binding to the gibberellin response complex in a barley alpha-amylase promoter. Plant Cell 5:1681-1692.

Triglia, T., M.G. Peterson, and D.J. Kemp. 1988. A procedure for in vitro amplification of DNA segments that lie outside the boundaries of known sequences. Nucleic Acids Res. 16:8186.

Yamaguchi-Shinozaki, K. and K. Shinozaki. 1994. A novel cis-acting element in an Arabidopsis gene is involved in responsiveness to drought, low-temperature, or high-salt stress. Plant Cell 6:251-264. 